\title{
ISOLATION, MOLECULER CHARACTERIZATION AND PATHOGENICITY OF METARHIZIUM ANISOPLIAE (METSCH.) SOROKIN (HYPOCREALES: CLAVICIPITACEAE) FROM SOIL IN ERZINCAN PROVINCE, TURKEY
}

\author{
KILIÇ, E. ${ }^{1 *}-$ YAZICI, A. ${ }^{2,3}-$ ÖRTÜCÜ, S..$^{2,3}$ \\ ${ }^{I}$ Department of Basic Pharmacutiel Science, Faculty of Pharmacy \\ Erzincan University, Erzincan, Turkey \\ ${ }^{2}$ Department of Molecular Biology and Genetics, Faculty of Science \\ Erzurum Technical University, Erzurum, Turkey \\ ${ }^{3}$ High Technology Research Center \\ Erzurum Technical University, Erzurum, Turkey \\ "Corresponding author \\ e-mail: enginfk@gmail.com; ORCID: 0000-0002-6838-5977
}

(Received $2^{\text {nd }}$ Nov 2018; accepted $28^{\text {th }}$ Feb 2019)

\begin{abstract}
Developing good microbial pesticides depends on isolating and knowing their pathogenicity. For this purpose, entomopathogenic Metarhizium anisopliae fungi were isolated from soils in Erzincan province and galleria bait method was used. Molecular identification of the isolates was performed by using ITS rDNA analysis. As a test organism, Galleria mellonella and Tenebrio molitor larvae were used and suspensions of $2 \times 10^{7}$ conidia $\mathrm{ml}^{-1}$ were prepared adding Tween $80 \AA$. Bioassays were performed by dipping technique and mortality was recorded daily for 12 days. Each assay consisted of 3 replicates with 10 insects larvae. Ten fungal isolates were obtained from the bait method. Based on classical and molecular methods, all fungal isolates were identified as M. anisopliae and deposited into GenBank database with MH104853 - MH104862 accession numbers. All isolates of M. anisopliae were pathogenic to G. mellonella and T. molitor with a mortality rate of $63.3 \pm 3.3 \%-83.3 \pm 3.3 \%$ and $30 \pm 5.8 \%$ $66.7 \pm 3.3 \%$, respectively 12 days after application. As a result, MaEMR1a and MaEO3 isolates can be applied as good biological control agents for pest insects.
\end{abstract}

Keywords: biological control, Metarhizium anisopliae, G. mellonella, T. molitor

\section{Introduction}

Entomopathogenic fungi (EPF) have an increasing prevalence in microbial control (Kılıç, E., 2009-Kılıç, E., 2014). EPF unlike other entomopathogenic microorganism (bacteria and viruses) which have to be ingested to cause diseases, typically infect insects by direct penetration of the cuticle followed by multiplication in the hemocoel (St. Leger et all., 2011). It is reported that EPF causes approximately, 60\% of insect diseases (Faria and Wraight, 2007). EPF can be an alternative to chemical pesticides and are considered as non-harmful biological control agents in terms of human and environmental health (Faria and Wraight, 2007). M. anisopliae has a global distribution as a member of the soil flora (Zimmermann, 1992). This species has been reported in soils from widely differing climatic zones (Gillespie, 1988; McCoy et al., 1988; Kılıç, 2017). Some researcher pointed out that many isolates of $M$. anisopliae have entomopathogenic activity against a range of arthropod pests (Gillespie, 1988; McCoy et al., 1988). Many scientists reported that $M$. anisopliae has been effective in controlling more than 200 species of insect pests $(\mathrm{Pu}$ and Li, 1996; Sabbour, 2002; 
Brooks and Wall, 2005; Quesada-Moraga et al., 2008; Shanley et al.; 2009; Dimbi et al., 2009; Dickson et al., 2010; Marius et al., 2011; Niassy et al., 2011).

In this paper, we isolated and characterized pathogenic fungi $M$. anisopliae for possible use as microbial control agent of $G$. mellonella and T. molitor and its pathogenicity was determined. Both insect species caused economic losses at storage.

\section{Material And Methods}

\section{Insect culture}

Galleria mellonella Linnaeus (Lepidoptera: Pyralidae) was collected from different beekepping in 2014 in Erzincan province. At the same time T. molitor (Coleoptera: Tenebrionidae) was collected from flour factories in Erzurum and storages in Erzincan provience. G. mellonella and T. molitor were grown under laboratory conditions $\left[\left(25^{\circ} \mathrm{C} \pm 2\right.\right.$ and $70 \% \pm 10$ R.H.) (16: 8 h (L:D)] (Zimmermann, 1986).

\section{Isolation and identification of entomopathogenic fungi}

Insect-associated fungi were isolated from soil samples by using 'Galleria bait method' (Zimmermann, 1986). The wax moth larvae, G. mellonella were reared continuously in constant darkness at $26^{\circ} \mathrm{C}$. The third or fourth instar larvae (approximately 30 days after hatching) were used as baits. Ten larvae were placed on the soil samples in each boxes and covered with a lid and incubated at $25 \pm 2{ }^{\circ} \mathrm{C}$ for two weeks. The larvae were examined on days 7 and 14 after inoculation. Surface of dead larvae were sterilized by $3 \%$ sodium hypochlorite for $3 \mathrm{~min}$ and then rinsed twice with sterile distilled water. After removing free water of the larvae surface, they were placed onto PDA plates. The fungi were identified using morphological characteristics of reproductive structures with the aid of relevant taxonomic literature (de Hoog, 1972; Samson et al., 1988; Tzean et al., 1997; Domsch et al., 1980; Humber, R., 1997; Humber, R., et al., 2012) (Table 1).

Table 1. Fungal material and their geographical origin (2014-2016)

\begin{tabular}{|c|c|c|c|}
\hline $\begin{array}{l}\text { Fungus } \\
\text { Species }\end{array}$ & Isolate Code & Substrate (Soil) & Geographical Origin of Isolates \\
\hline \multirow{10}{*}{ 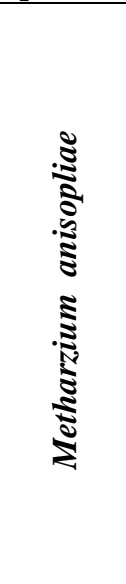 } & MaEMR1a & Vegetable Field & ERZINCAN, Turkey \\
\hline & MaEMR2b & Vegetable Field & ERZİNCAN-Üzümlü, Turkey \\
\hline & MaEK1a & Vegetable Field & ERZINCAN-Kemah, Turkey \\
\hline & MaEİ3 & Field (Barly-Weat) & ERZINCAN-İliç, Turkey \\
\hline & MaEKLY1a & Fruit Garden & ERZINCAN-Kemaliye, Turkey \\
\hline & MaER3 & Field (Barly-Weat) & ERZINCAN-Refahiye, Turkey \\
\hline & MaEM1 & Vegetable Field & ERZINCAN-Mercan, Turkey \\
\hline & MaET3 & Field (Barly-Weat) & ERZINCAN-Tercan, Turkey \\
\hline & MaEÇ3 & Field (Barly-Weat) & ERZINCAN-Çayırlı, Turkey \\
\hline & $\mathrm{MaEO} 3$ & Field (Barly-Weat) & ERZINCAN-Otlukbeli, Turkey \\
\hline
\end{tabular}


The identification of the isolated entomopathogenic fungi were performed using ITS. For this purpose, ITS1 (TCCGTAGGTGAACCTGCGG) and ITS4 (TCCTCCGCTTATTGATATGC) primers were used for the PCR (White et al., 1990). Genomic DNA was isolated from fungal biomass following the protocols of the EcoSpin. Genomic DNA isolation kit (EcoTec Biotecnology, Türkey). The PCR cycling conditions were: $2 \mathrm{~min}$ at $95^{\circ} \mathrm{C}$, followed by 30 cycles at $95^{\circ} \mathrm{C}$ for $45 \mathrm{~s}, 55^{\circ}$ $\mathrm{C}$ for $60 \mathrm{~s}, 72^{\circ} \mathrm{C}$ for $60 \mathrm{~s}$ with a final extension step of $72^{\circ} \mathrm{C}$ for $10 \mathrm{~min}$. PCR products were analyzed in $1 \%(\mathrm{w} / \mathrm{v})$ agarose gels visualized by UV after staining with EtBr. The products were purified by following the protocols of the EcoSpin PCR Purification Kit (EcoTec Biotecnology, Türkey). After purification, ITS rDNA were sequenced in both directions with 4 same primers at OLIGOMER Biotecnology, Turkey. Sequences chromatograms were assembled into one complete sequence using Bioedit Program (Hall, 1999) and the sequences were compared to all known sequences by the use of BLASTN 2.2.26+ program (Zhang et al. 2000) and deposited into GenBank (Table 2).

\section{Preparation of conidial suspension}

M. anisopliae isolates conidia were harvested by scraping the surface of 3-weekold sporulating cultures grown on potato dextrose agar (PDA) in petri dishes in an incubation at $25^{\circ} \mathrm{C} \pm 2$ for three weeks from sowing. Fungus spores were harvested after three weeks by pouring a suspension that was prepared by adding $0.01 \%$ Tween 80 in sterilised and distilled water in a sterilized glass Erlenmeyer flask, into the Petri dish developed by $M$. anisopliae. Liquid mixture with fungi was drained into the sterilised glass Erlenmeyer flasks from cheese cloth. Then it was rinsed on a rinsing device for five minutes. After that, the spores were counted in the suspensions using a haemocytometer to $2 \times 10^{7}$ spores/ml (Klingen et al., 2002a; Klingen et al., 2002b; Klingen et al., 2002c; Vänninen et al., 1999).

\section{Incubation of fungal spores and its treatment on G. mellonella and T. molitor}

Dipping technique was used and the fungus isolate was dipped in the tested spore suspensions for 10 second, then left to dry at room temperature. Every petri dish included 10 larvae for the experiments. For control treatment, the same process was followed but $3 \mathrm{ml}$ of sterilized and distilled water with $0.01 \%$ of Tween 80 was used instead of fungus isolate for the dipping. After all of the application petri dishes were stored in the incubator $\left(25^{\circ} \mathrm{C} \pm 2\right)$ (Butt et al., 1994; Butt, 2002; Safavi et al., 2010). Mortality was assessed daily for 12 days by direct inspection for any signs of mortality. The experiment was replicated three times.

\section{Statistical analysis}

The experimental design was a randomized complete block with three replicates, and each replicate consisted of 10 larvae. The collected data were analyzed by oneway ANOVA test using SPSS 15.0 and means were compered by Duncan test. 


\section{Results}

All fungal isolates were pathogenic to G. mellonella and T. molitor with a mortality rate between $63.3 \pm 3.3 \%-83.3 \pm 3.3 \%$ and $30 \pm 5.8 \%-66.7 \pm 3.3 \%$, respectively after 12 days from application. Microscopic investigations confirmed mycosis and fungi were reisolated from all dead individuals.

In this study, a total of 10 different isolates belonging to the genera Metarhizium were obtained. Based on clasicall and molecular methods, all fungal isolates were identified as $M$. anisopliae and deposited in the GenBank database under the accession numbers MH104853 - MH104862 as seen in Table 2.

Table 2. Fungal material and their geographical origin (2014-2016)

\begin{tabular}{|c|c|c|}
\hline Species & Isolate Code & GenBank Accession Numbers \\
\hline \multirow{10}{*}{ 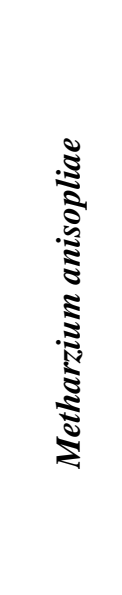 } & MaEMR1a & MH104853 \\
\hline & MaEMR2b & MH104854 \\
\hline & MaEK1a & MH104855 \\
\hline & MaEi̇3 & MH104856 \\
\hline & MaEKLY1a & MH104857 \\
\hline & MaER3 & MH104858 \\
\hline & MaEM1 & MH104859 \\
\hline & MaET3 & MH104860 \\
\hline & MaEÇ3 & MH104861 \\
\hline & MaEO3 & MH104862 \\
\hline
\end{tabular}

Isolates of MaEMR1a, MaEM1 and MaEO3 caused mortality in more than $80 \%$ of G. mellonella larvae. There was no significant difference between these isolates $(\mathrm{p}<0.05)$. However, isolate MaEM1 led to earlier mortality than the others. Mortality was found to increase with time. The mortality percentages of isolates against $G$. mellonella are depicted in Table 3.

The most virulent isolates against T. molitor were MaEO3, MaET3, MaEKLY1a and MaEMR1a, which caused 60, 63.3, 66.7 and 63.3\% mortality, respectively after 12 days from application. As seen in Table 4, M. anisopliae isolate MaEMR1a was consistently more virulent than other isolates because mortality caused by this isolate was found to be significantly different $(\mathrm{p}<0.05)$ on the $10^{\text {th }}$ day.

It is observed that the death rates have increased as time progressed. As the entomopathogenic fungi feed in the host and complete their development, secondary metabolites secreted to kill the host are exposed and the host is dying more rapidly. At the same time, the fungus develops inside the host and breaks down the integument of the intestine and hyphae appear on the host body surface. 
Table 3. Mortality of M. anisopliae isolates against G. mellonella larvae (\%)

\begin{tabular}{|c|c|c|c|c|c|c|c|c|c|c|}
\hline Isolates & 3.day & 4.day & 5.day & 6.day & 7.day & 8.day & 9.day & 10.day & 11.day & 12.day \\
\hline MaEMR1a & $0^{\mathbf{a}}$ & $16.7^{ \pm 6.7 a b}$ & $23.3^{ \pm 6.7 a}$ & $40^{ \pm \mathbf{a} \mathbf{a} b}$ & $43.3^{ \pm 3.3 c}$ & $46.7^{ \pm 3.3 \mathrm{~cd}}$ & $60^{ \pm 0 \mathrm{bcd}}$ & $63.3^{ \pm 3.3 b c}$ & $70^{ \pm \mathbf{a} \mathbf{a b}}$ & $83.3^{ \pm 3.3 a}$ \\
\hline MaEMR2b & $0^{\mathbf{a}}$ & $16.7^{ \pm 3.3 a b}$ & $30^{ \pm \mathbf{0 a}}$ & $40^{ \pm \mathbf{0 a b}}$ & $46.7^{ \pm 3.3 b c}$ & $56.7^{ \pm 3.3 a b c}$ & $63.3^{ \pm 3.3 a b c}$ & $66.7^{ \pm 3.3 b c}$ & $73.3^{ \pm \mathbf{3 . 3} \mathbf{a b}}$ & $76.7^{ \pm \mathbf{3 . 3} \mathbf{a b}}$ \\
\hline MaEK1a & $0^{\mathrm{a}}$ & $13.3^{ \pm \mathbf{3 . 3 a b c}}$ & $23.3^{ \pm 3.3 \mathrm{a}}$ & $33.3^{ \pm \mathbf{8 . 9 b}}$ & $40^{ \pm 5.8 c}$ & $40^{ \pm 5.8 \mathrm{~d}}$ & $50^{ \pm 0 \mathrm{~d}}$ & $63.3^{ \pm 3.3 b c}$ & $63.3^{ \pm 3.3 b c}$ & $76.7^{ \pm \mathbf{3 . 3 a b}}$ \\
\hline MaEİ3 & $0^{\mathbf{a}}$ & $10^{ \pm 0 \mathbf{b c}}$ & $23.3^{ \pm \mathbf{3 . 3 a}}$ & $33.3^{ \pm \mathbf{3 . 3 b}}$ & $40^{ \pm 5.8 c}$ & $46.7^{ \pm 3.3 \mathrm{~cd}}$ & $56.7^{ \pm 3.3 \mathrm{~cd}}$ & $63.3^{ \pm 3.3 b c}$ & $73.3^{ \pm \mathbf{3 . 3} \mathbf{a b}}$ & $76.7^{ \pm 3.3 a b}$ \\
\hline MaEKLY1a & $0^{\mathbf{a}}$ & $13.3^{ \pm \mathbf{3 . 3} \mathbf{a b c}}$ & $30^{ \pm 5.8 \mathbf{a}}$ & $36.7^{ \pm 6.7 b}$ & $40^{ \pm 5.8 c}$ & $53.3^{ \pm \mathbf{3 . 3 b c}}$ & $60^{ \pm 0 \mathrm{bcd}}$ & $60^{ \pm 5.8 c}$ & $60^{ \pm 5.8 c}$ & $63.3^{ \pm 3.3 c}$ \\
\hline MaER3 & $3.3^{ \pm 3.3 \mathrm{a}}$ & $20^{ \pm 5.8 \mathbf{a b}}$ & $36.7^{ \pm \mathbf{3 . 3 a}}$ & $46.7^{ \pm 6.8 \mathrm{ab}}$ & $50^{ \pm 5.8 b c}$ & $56.7^{ \pm 3.3 \mathrm{abc}}$ & $63.3^{ \pm \mathbf{3 . 3} \mathbf{a b c}}$ & $73.3^{ \pm \mathbf{3 . 3} \mathbf{a b}}$ & $73.3^{ \pm \mathbf{3 . 3} \mathbf{a b}}$ & $73.3^{ \pm \mathbf{3 . 3} \mathbf{a b}}$ \\
\hline MaEM1 & $0^{\mathrm{a}}$ & $20^{ \pm 5.8 \mathbf{a b}}$ & $26.7^{ \pm 3.3 a}$ & $43.3^{ \pm \mathbf{3 . 3} \mathbf{a b}}$ & $53.3^{ \pm \mathbf{3} .3 \mathrm{bc}}$ & $63.3^{ \pm \mathbf{3 . 3} \mathbf{a b}}$ & $70^{ \pm 0 \mathbf{a b}}$ & $80^{ \pm 0 \mathrm{a}}$ & $80^{ \pm 0 \mathrm{a}}$ & $83.3^{ \pm 3.3 a}$ \\
\hline MaET3 & $3.3^{ \pm 3.3 \mathrm{a}}$ & $16.7^{ \pm 3.3 a b}$ & $30^{ \pm 5.8 \mathbf{a}}$ & $46.7^{ \pm 3.3 a b}$ & $53.3^{ \pm \mathbf{3 . 3 b c}}$ & $56.7^{ \pm 3.3 \mathrm{abc}}$ & $63.3^{ \pm 3.3 a b c}$ & $63.3^{ \pm 3.3 b c}$ & $70^{ \pm \mathbf{0 a b}}$ & $70^{ \pm 0 \mathbf{b c}}$ \\
\hline MaEÇ3 & $0^{\mathbf{a}}$ & $10^{ \pm 5.8 b c}$ & $26.7^{ \pm 3.3 a}$ & $43.3^{ \pm \mathbf{3} . \mathbf{3 a b}}$ & $66.7^{ \pm 3.3 a}$ & $66.7^{ \pm 3.3 a}$ & $66.7^{ \pm 3.3 \mathrm{abc}}$ & $70^{ \pm \mathbf{0 a b c}}$ & $73.3^{ \pm \mathbf{3 . 3} \mathbf{a b}}$ & $76.7^{ \pm 3.3 a b}$ \\
\hline MaEO3 & $3.3^{ \pm 3.3 \mathrm{a}}$ & $26.7^{ \pm \mathbf{3 . 3 a}}$ & $36.7^{ \pm 3.3 a}$ & $53.3^{ \pm 3.3 a}$ & $60^{ \pm \mathbf{0 a b}}$ & $66.7^{ \pm 3.3 \mathrm{a}}$ & $73.3^{ \pm \mathbf{3 . 3 a}}$ & $73.3^{ \pm \mathbf{3 . 3} \mathbf{a b}}$ & $76.7^{ \pm 3.3 a}$ & $83.3^{ \pm \mathbf{3 . 3 a}}$ \\
\hline Control & $0^{\mathbf{a}}$ & $0^{\mathbf{c}}$ & $0^{\mathbf{b}}$ & $0^{\mathbf{c}}$ & $0^{\mathbf{d}}$ & $0^{\mathbf{e}}$ & $0^{\mathbf{e}}$ & $0^{\mathbf{d}}$ & $0^{\mathbf{d}}$ & $3.3^{ \pm 3.3 \mathrm{~d}}$ \\
\hline
\end{tabular}

*All values are mean \pm standard error of three determinations $(n=3)$. Same alphabet letters in the same column are not significantly different at $\mathrm{p}<0.05$.

Table 4. Mortality of M. anisopliae isolates against Tenebrio molitor larvae (\%)

\begin{tabular}{|c|c|c|c|c|c|c|c|c|c|c|}
\hline Isolates & 3.day & 4.day & 5.day & 6.day & 7.day & 8.day & 9.day & 10.day & 11.day & 12.day \\
\hline MaEMR1a & 0 & $10^{ \pm 5.8 a b}$ & $16.7^{ \pm 3.3 b c d}$ & $20^{ \pm 5.8 \mathrm{cde}}$ & $20^{ \pm 5.8 \mathrm{~cd}}$ & $36.7^{ \pm 3.3 b c d}$ & $40^{ \pm 5.8 \mathrm{bcd}}$ & $53.3^{ \pm \mathbf{3 . 3 a b c}}$ & $56.7^{ \pm 3.3 a b}$ & $63.3^{ \pm 3.3 a}$ \\
\hline MaEMR2b & 0 & $6.7^{ \pm 3.3 \mathrm{ab}}$ & $13.3^{ \pm 8.9 \text { cde }}$ & $20^{ \pm 5.8 \mathrm{cde}}$ & $26.7^{ \pm 12 b c d}$ & $30^{ \pm 11.5 \text { cde }}$ & $43.3^{ \pm \mathbf{8 . 9} \mathbf{a b c}}$ & $43.3^{ \pm 8.9 \mathrm{~cd}}$ & $43.3^{ \pm 8.9 b c}$ & $53.3^{ \pm \mathbf{8 . 9} \text { abc }}$ \\
\hline MaEK1a & 0 & $10^{ \pm 5.8 \mathbf{a b}}$ & $20^{ \pm 5.8 \mathbf{a b c d}}$ & $26.7^{ \pm \mathbf{3 . 3 a b c}}$ & $30^{ \pm 5.8 \mathbf{a b c}}$ & $43.3^{ \pm \mathbf{3 . 3 a b c}}$ & $53.3^{ \pm \mathbf{3 . 3 a b}}$ & $56.7^{ \pm 3.3 \mathrm{abc}}$ & $56.7^{ \pm 3.3 \mathbf{a b}}$ & $56.7^{ \pm \mathbf{3 . 3 a b}}$ \\
\hline MaEİ3 & 0 & $6.7^{ \pm 3.3 \mathrm{ab}}$ & $13.3^{ \pm 3.3 \text { cde }}$ & $13.3^{ \pm \mathbf{3 . 3}}$ & $23.3^{ \pm \mathbf{3 . 3 e d}}$ & $26.7^{ \pm \mathbf{3 . 3 d e}}$ & $26.7^{ \pm 3.3 \mathrm{de}}$ & $33.3^{ \pm \mathbf{3 . 3 d e}}$ & $33.3^{ \pm \mathbf{3 . 3 c}}$ & $40^{ \pm 5.8 \mathrm{~cd}}$ \\
\hline MaEKLY1a & 0 & $20^{ \pm \mathbf{5 . 8} \mathbf{a}}$ & $30^{ \pm 5.8 a b}$ & $36.7^{ \pm \mathbf{3 . 3 a}}$ & $36.7^{ \pm 3.3 \mathrm{abc}}$ & $53.3^{ \pm \mathbf{3 . 3 a}}$ & $53.3^{ \pm \mathbf{3 . 3 a b}}$ & $63.3^{ \pm \mathbf{3 . 3 a}}$ & $63.3^{ \pm \mathbf{3 . 3 a}}$ & $66.7^{ \pm 3.3 \mathrm{a}}$ \\
\hline MaER3 & 0 & $3.3^{ \pm \mathbf{3 . 3} \mathbf{b}}$ & $10^{ \pm 5.8 d e}$ & $10^{ \pm 5.8 \mathrm{ef}}$ & $10^{ \pm 5.8 d e}$ & $20^{ \pm 5.8 e}$ & $20^{ \pm 5.8 e}$ & $23.3^{ \pm \mathbf{3 . 3 e}}$ & $30^{ \pm 5.8 c}$ & $30^{ \pm 5.8 d}$ \\
\hline MaEM1 & 0 & $20^{ \pm \mathbf{5 . 8} \mathbf{a}}$ & $26.7^{ \pm 3.3 a b c}$ & $30^{ \pm 0 \text { abc }}$ & $33.3^{ \pm 3.3 a b c}$ & $43.3^{ \pm 3.3 a b c}$ & $46.7^{ \pm 3.3 \mathrm{abc}}$ & $46.7^{ \pm 3.3 b c d}$ & $50^{ \pm 5.8 a b}$ & $53.3^{ \pm \mathbf{3 . 3 a b c}}$ \\
\hline MaET3 & 0 & $10^{ \pm 5.8 a b}$ & $23.3^{ \pm 3.3 a b c d}$ & $23.3^{ \pm 3.3 b c d}$ & $43.3^{ \pm \mathbf{3 . 3} \mathbf{a b}}$ & $43.3^{ \pm 3.3 \mathrm{abc}}$ & $46.7^{ \pm 3.3 \mathbf{a b c}}$ & $60^{ \pm 5.8 \mathbf{a b}}$ & $63.3^{ \pm \mathbf{3 . 3 a}}$ & $63.3^{ \pm \mathbf{3 . 3 a}}$ \\
\hline MaEÇ3 & 0 & $10^{ \pm 0 a b}$ & $13.3^{ \pm 3.3 \text { cde }}$ & $13.3^{ \pm \mathbf{3 . 3}}$ & $20^{ \pm \mathbf{5 . 8 c d}}$ & $30^{ \pm 5.8 \mathrm{cde}}$ & $36.7^{ \pm \mathbf{3 . 3 e d}}$ & $43.3^{ \pm \mathbf{3 . 3} \mathbf{c d}}$ & $43.3^{ \pm \mathbf{3 . 3 b c}}$ & $43.3^{ \pm \mathbf{3 . 3 b c d}}$ \\
\hline MaEO3 & 0 & $13.3^{ \pm \mathbf{3 . 3 a b}}$ & $33.3^{ \pm \mathbf{3 . 3} \mathbf{a}}$ & $33.3^{ \pm \mathbf{3 . 3 a b}}$ & $46.7^{ \pm 3.3 a}$ & $50^{ \pm \mathbf{a a b}}$ & $56.7^{ \pm 6.7 \mathrm{a}}$ & $60^{ \pm 5.8 \mathbf{a b}}$ & $60^{ \pm 5.8 \mathrm{a}}$ & $60^{ \pm 5.8 \mathrm{a}}$ \\
\hline Control & 0 & $0^{\mathbf{b}}$ & $0^{\mathbf{e}}$ & $0^{\mathbf{f}}$ & $0^{\mathbf{e}}$ & $0^{\mathbf{f}}$ & $0^{\mathbf{f}}$ & $0^{\mathbf{f}}$ & $0^{\mathbf{d}}$ & $0^{\mathbf{e}}$ \\
\hline
\end{tabular}

*All values are mean \pm standard error of three determinations $(n=3)$. Same alphabet letters in the same column are not significantly different at $\mathrm{p}<0.05$. 


\section{Discussion}

Entomopathogenic fungi are used in the control of harmful insects and especially in the Integred pest management system (IPM) and they are used successfully nowadays. It is important to know the virulence of the newly developed mycoinsecticides, the killing rates, the molecular characterization of these fungi and their genetic structure as soon as possible.

According to this study, MaEMR1a, MaEM1 and MaEO3 isolates of M. anisopliae have been determined to have potential to suppress $G$. mellonella larvae; MaEO3, MaET3, MaEKLY1a and MaEMR1a isolates have potential to suppress T. molitor larvae. Among them these isolates, MaEMR1a and MaEO3 isolates possessed a good potential against both $G$. mellonella and T. molitor larvae. Our results overlap with other pataogentite tests on T. molitor and G. mellonella larvae (Pajar et al., 2013; Mora, E.A.M., 2016). Our results indicated that these two isolates (MaEMR1a and MaEO3) have a broad host range and can be used as biocontrol agents for G. mellonella and T. molitor and also they can be used as storages of biological control agents.

Acknowledgements. The EPF isolation part of this study was supported by the Erzincan University Research Foundation (FEN-A-300614-0104).

\section{REFERENCES}

[1] Alves, S. B., Lopes, R. B. (2008): Controle microbiano de pragas na América Latina: avanços e desafios. - Piracicaba: FEALQ: 414.

[2] Bischoff, J. F., Rehner, S. A., Humber, R. A. (2009): A multilocus phylogeny of the Metarhizium anisopliae lineage. - Mycologia 101: 512- 530.

[3] Brooks, A., Wall, R. (2005): Horizontal transmission of fungal infection by Metarhizium anisopliae in parasitic Psoroptes mites (Acari: Psoroptidae). - Biol Control 34(1): 58-65.

[4] But, T. M., Ibrahim, L., Ball, B. V., Clark, S. J. (1994): Pathogenicity of the entomogenous fungi Metarhizium anisopliae and Beauveria bassiana against crucifer pests and the honey bee. - Biocont Sci Technol 4: 207-214.

[5] Butt, T. M. (2002): Use of Entomogenous Fungi for the Control of Insect Pests: 111-134. - In: Kempken, F. (ed.) Agricultural Applications, Springer Berlin Heidelberg, Berlin, 388.

[6] Dickson, W. L., Robert, D. S., Edith, P. M., Deogratius, R. K., Ladslaus, L. M., Tanya, L. R., Fredros, O. O. (2010): An extra-domiciliary method of delivering entomopathogenic fungus, Metarhizium anisopliae IP 46 for controlling adult populations of the malaria vector, Anopheles arabiensis. - Parasite Vector 3(18): 1-6.

[7] Dimbi, S., Maniania, N. K., Ekesi, S. (2009): Effect of Metarhizium anisopliae inoculation on the mating behavior of three species of African Tephritid fruit flies, Ceratitis capitata, Ceratitis cosyra and Ceratitis fasciventris. - Biol Control 50(2): 111116.

[8] Domsch, K. H., Games, W., Anderson, T. H. (1980): Compendium of Soil Fungi Academic press. London.

[9] Faria, M. R., Wraight, S. P. (2007): Mycoinsecticides and mycoacaricides: A comprehensive list with worldwide coverage and international classification of formulation types. - Biological Control 43: 237-256. 
[10] Gillespie, A. T. (1988): Use of fungi to control pest of agricultural importance. - In: Burge, M. N. (ed.) Fungi in biological control systems: 37-60, Manchester University Press.

[11] Hall, T. A. (1999): BioEdit: a user-friendly biological sequence alignment editor and analysis program for Windows 95/98/NT. - Nucleic Acids Symp Ser 41: 95-98.

[12] De Hoog, G. S. (1972): The genera Beauveria, Isaria, Tritirachium and Acrodontium gen.nov - Study Mycol 1:1-41.

[13] Humber, R. (1997): Entomopathogenic Fungal Identification: 153-185 - In: Lacey, L. A. (ed.) Manual of Techniques In Insect Pathology San Diego.

[14] Humber, R., Gryganskyi, A. P., Vilgalys, R. (2012): Phylogenetic reclassification raises new respect-and a new phylum!- for Entomophthorales. - Mol Phylogenet Evol 65(2): 682-94.

[15] Kılıç, E. (2014): Biopesticides marked and Turkey. - International Conference on Biopesticides 7. Side Antalya, Turkey.

[16] Kılıç, E. (2017): Isolation entomopathogenıc fungi from Erzincan provience. $-6^{\text {th }}$ Entomopathogens and Microbial Control Congress. Tokat, Turkey.

[17] Kılıç, E., Yıldırm, E., İskender, N. A., Algur, Ö. F. (2009): Pathogenity of Beuveria bassiana (balsomo) Villenium 1826 (Deuteromycotina: Hypomycetes) isolates to various development stages of Bemicia tabaci (Homoptera: aleyrodiade) - Bio-Science research Bulletin 25: 17-28.

[18] Klingen, I., Eilenberg, J., Meadow, R. (2002a): EVects of farming system, Weld margins and bait insect on the occurrence of insect pathogenic fungi in soils. - Agric Ecosyst Environ 91: 191-198.

[19] Klingen, I., Hajek, A., Meadow, R., Renwick, J. A. A. (2002b): EVect of brassicaceous plants on the survival and infectivity of insect pathogenic fungi. - BioControl 47: 411425.

[20] Klingen, I., Meadow, R., Aandal, T. (2002c): Mortality of Delia Xoralis, Galleria mellonella and Mamestra brassicae treated with insect pathogenic hyphomycetous fungi. - J Appl Entomol 126: 231-237.

[21] Marius, H., Godwin, P. K., Michael, S., Galina, G., Itamar, G. (2011): Pathogenicity of the entomopathogenic fungus Metarhizium anisopliae to the red-legged tick, Rhipicephalus evertsi. - Afr J Biotechnol 3(7): 68-72.

[22] McCoy, C. W., Samson, R. A., Boucias, D. G. (1988): Entomogenous fungi. - In: Ignoffo, C. M., Mandava, N. B. (eds.) Handbook of natural pesticides. Boca, Ra-ton, Mr ic, Fla: Mr ic press. Microbial insectides 5, part A. Entomogenous protozoa and Fungi.

[23] Mora, A. E. M., Chaco-Orozco, J. G., Harakava, R., Rouws, J. R. C., Fraga, M. E. (2016): Molecular characterization and virulence of Beauveria bassiana and Metarhizium anisopliae against Galleria mellonella (Lepidoptera: Pyralidae) and Tenebrio molitor (Coleoptera: Tenebrionidae) larvae. - African Journal of Microbiology Research 10(9): 662-668.

[24] Niassy, S., Diarra, K., Ndiaye, S., Niassy, A. (2011): Pathogenicity of local Metarhizium anisopliae var. acridum strains on Locusta migratoria migratorioides Reiche and Farmaire and Zonocerus variegatus Linnaeus in Senegal. - Afr J Biotechnol 10(1): 28-33.

[25] Pajar, J. A. L., Cabahug, D. V., Sumaya, N. H. N., Martinez, J. G. T., Madamba, R. S. B., Rivero, H. I. (2013): Virulence of Local Metarhizium spp.Isolates Against Tenebrio Molitor (Linn): An Initial Comparison with Non-Native and Commercially Available Strains. - International Journal of the Computer, the Internet and Management 21(1): 4852.

[26] Pu, Z. N., Li, Z. Z. (eds.) (1996): Insect Mycology - Anhui Publishing House of Science and Technology, Hefei, China (in Chinese). 
[27] Quesada-Moraga, E., Martin-Carballo, I., Garrido-Jurado, I., Santiago-Álvarez, C. (2008): Horizontal transmission of Metarhizium anisopliae among laboratory populations of Ceratitis capitata (Wiedemann) (Diptera: Tephritidae). - Biol Control 47(6): 115-124

[28] Sabbour, M. M. (2002): The role of chemical additives in enhancing the efficacy of Beauveria bassiana and Metarhizium anisopliae against the potato tuber moth Phthorimaea operculella (Zeller) (Lepidoptera: Gelechiidae). - Pak J Biol Sci 5(11): 1155-1159.

[29] Safavi, S. A., Kharrazi, A., Rasoulian, G. R., Bandani, A. R. (2010): Virulence of some isolates of entomopathogenic fungus, Beauveria bassiana on Ostrinia nubilalis (Lepidoptera: Pyralidae) larvae. - Journal of Agricultural Science and Technology 12(1): 13-21.

[30] Samson, R. A., Evans, H. C., Latge, J. P. (1988): Atlas of Entomopathogenic Fungi. Springer-Verlag, New York: 187.

[31] Shanley, R. P., Keena, M., Wheeler, M. M., Leland, J., Hajek, A. E. (2009): Evaluating the virulence and longevity of non-woven fiber bands impregnated with Metarhizium anisopliae against the Asian long horned beetle, Anoplophora glabripennis (Coleoptera: Cerambycidae). - Biol Control 50(4): 94-102.

[32] St. Leger, R. J., Wang, C., Fang, W. (2011): New Perspectives On Insect Pathogens. Fungal Biology Reviews 25: 84-88.

[33] White, T. J., Bruns, T., Lee S., Taylor, J. (1990): Amplification and direct sequencing of fungal ribosomal RNA genes for phylogenetics. - In: Innis, M. A., Gelfand, D. H., Sninsky, J. J., White, T. J. (eds.) PCR Protocols: a guide to methods and applications. Academic Press, New York: 315-322.

[34] Tzean, S. S., Hsieh, L. S., Wu, W. J. (1997): Atlas of Enomopathogenic Fungi from Taiwan. - Council of Agriculture, Taiwan, R.O.C.: 214.

[35] Vänninen, I., Hokkanen, H., Tyni-Juslin, J. (1999): Attempts to control cabbage root Xies, Delia radicum (L.) and Delia Xoralis (Fall.) (Dipt., Anthomyiidae), with entomopathogenic fungi: laboratory and greenhouse tests. - J Appl Entomol 123: 107113.

[36] Zhang, Z., Schwartz, S., Wagner, L., Miller, W. (2000): A greedy algorithm for aligning DNA sequences. - Journal of Computational Biology 7: 203-214.

[37] Zimmermann, G. (1986): The Galleria bait method for detection of entomopathogenic fungi in soil. - J Appl Entomol 102: 213-215.

[38] Zimmermann, G. (1992): Pflanzenschutz-Nachr. - Bayer 45: 113-128. 